Full Research Paper

\title{
Fusarium Graminearum Growth Inhibition Due to Glucose Starvation Caused by Osthol
}

\section{Zhiqi Shi *, Shouguo Shen, Wei Zhou, Fei Wang and Yongjian Fan}

Food Safety Research and Service institute, Jiangsu Academy of Agricultural Sciences, Nanjing 210014, P.R. China; E-mails: chenhao@jaas.ac.cn; zhouwei@jaas.ac.cn; lyq@jaas.ac.cn; wangcm@jaas.ac.cn

*Author to whom correspondence should be addressed; Tel. +86-25-84391863; Fax:+ 86-2584391260; E-mail: shizhiqi@jaas.ac.cn

Received: 13 September 2007; in revised form: 28 February 2008 / Accepted: 12 March 2008 / Published: 14 March 2008

\begin{abstract}
The effects of osthol, a plant coumarin, on morphology, sugar uptake and cell wall components of Fusarium graminearum were examined in vitro by electron microscopy, ${ }^{14} \mathrm{C}$-labelling and enzyme activity detection. The results revealed that osthol could inhibit the hypha growth of $F$. graminearum by decreasing hyphal absorption to reducing sugar. After treatment with $100 \mu \mathrm{g} \cdot \mathrm{mL}^{-1}$ osthol for $24 \mathrm{~h}$, many hyphal fragments of F. graminearum appeared. Microscopy observation showed that the cell walls of hyphal fragments blurred and the organelles of the cells degraded with the increasing vacuoles. The $N$-acetyl-D-glucosamine contents and chitinase activity both increased when hypha were treated with $100 \mu \mathrm{g} \cdot \mathrm{mL}^{-1}$ osthol, whereas the activity of $\beta$-1,6-glucanase remained unchanged. When $F$. graminearum fed with ${ }^{14} \mathrm{C}$ glucose was treated with $100 \mu \mathrm{g} \cdot \mathrm{mL}^{-1}$ osthol, glucose contents decreased to the lowest level, while the contents in non-osthol treated controls remained unchanged. These results suggested that chitinase activity might be related to glucose starvation under osthol treatment, and that the appearance of hyphae fragments maybe the results of the promoted chitinase activity which itself triggered chitin degradation.
\end{abstract}

Keywords: Fusarium graminearum; osthol; inhibition; glucose starvation; chitinase activity 


\section{Introduction}

Fusarium head blight (FHB), caused by Fusarium graminearum Schwabe (teleomorph: Gibberella zeae), is a major disease of wheat and has resulted in heavy yield losses in many areas of China, the largest wheat producer in the World [1,2]. In eastern China, the continuous use of benzimidazole fungicides has caused the appearance of fungicide resistant strains in F. graminearum and these resistant populations are becoming dominant [3]. Lacking effective resistant cultures, plant disease control in China nowadays still relies mainly on the application of chemical agents. With the application of the PRC Agricultural Product Quality Security law, research and development of novel fungicides with high safety and efficiency has become a hot topic of crop protection research.

Osthol (7-methoxy-8-[3-methylpent-2-enyl] coumarin), a plant coumarin, is isolated from the dried fruits of Cnidium Monnieri which have been used as a herbal medicine since ancient times in China [4]. Recent pharmacological studies have revealed its antiallergic [5, 6], antiosteoporotic [7], and antiinflammatory [8] activities. Its antifungal activity was proven on Alternaria alternate, A. ergillus sp., Cryptococuus neoformans, etc. [9]. Our previous studies also showed that osthol has a wide antifungal activity, with the $\mathrm{EC}_{50}$ values ranging from $21.15 \mu \mathrm{g} \cdot \mathrm{mL}^{-1}$ to $61.62 \mu \mathrm{g} \cdot \mathrm{mL}^{-1}$ against Botrytis cinerea, Colletotrichum mllsae, Fusarium graminearum, Phytophora capsici, Sclerotinia sclerotiorum and other phytopathogenic fungi [10]. So, as a natural plant toxin, osthol has been developed into biopesticides in our lab, however, its antifungal mechanism and mode of action against phytopathogens still remains unknown. Here, we investigated the effects of osthol on F. graminearum, pathogen causing FHB, and a preliminary mechanism of action was studied and discussed.

\section{Results and Discussion}

\subsection{Results}

\subsubsection{Effects of osthol on hyphal growth}

In vitro antifungal assays in our previous study had demonstrated that osthol could inhibit the growth of hyphae of $F$. graminearum with its $\mathrm{EC}_{50}$ value $56.94 \mu \mathrm{g} \cdot \mathrm{mL}^{-1}$ [10]. Here, the results of disc diffusion test (Figure 1) and biomass assay (Figure 2) further confirmed its inhibitory effects on hyphal growth of $F$. graminearum. With the increase of osthol concentration in PDA medium plates, the inhibitory effect against $F$. graminearum was enhanced through reducing the growth diameter on plates (Figure 1). As shown in Figure 2, osthol began to affect the hyphal growth when its concentration beyond $25 \mu \mathrm{g} \cdot \mathrm{mL}^{-1}$. And the dry weight of hyphae almost behalved when osthol was used

$100 \mu \mathrm{g} \cdot \mathrm{mL}^{-1}$. We did not find hyphal fragment on osthol-treated PDA medium plates. But through microscope observation, we found that more branches appeared from the top edge of hypha treated with osthol (date not shown).

\subsubsection{Effects of osthol on hyphae morphology}

After treatment with $100 \mu \mathrm{g} \cdot \mathrm{mL}^{-1}$ osthol for 24 hours, the hyphae of $F$. graminearum broke into large fragments (Figure 3B). But these fragments remained actively which could be proved by the 
result of fragments reinoculation test shown in Figure 3C. Furthermore, the TEM observation showed that the osthol-treated hyphae presented degenerative changes compared to the controls (Figure 4). There are large vesicles appearing in osthol-treated cells (Figure 4C, E) and most of these cell walls were becoming blurring after $24 \mathrm{~h}$ treatment with $100 \mu \mathrm{g} \cdot \mathrm{mL}^{-1}$ osthol (Figure $4 \mathrm{E}$ ). In addition, nuclei in cells of blank and solvent controls can be clearly distinguished (Figure 4A, B), however, this was changed in osthol-treated cells. We could not found visible boundary of nucleus (Figure 4C).

Figure 1. Dose-dependent inhibition of osthol to hyphal diametral growth of $F$. graminearum. Concentration of osthol in PDA medium in Petri plates 1 to 6 was 0, 6.25, 12.5, 25, 50 and $100 \mu \mathrm{g} \cdot \mathrm{mL}^{-1}$, respectively. Experiments were repeated 3 times and each time was done in triplicate.

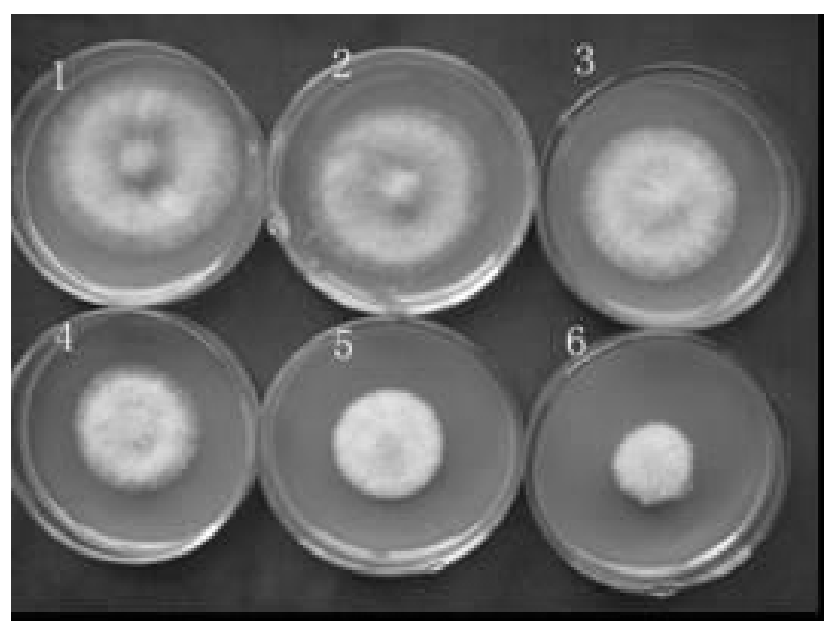

Figure 2. Effect of osthol on hyphal dry weight of $F$. graminearum. Mycelia of F. graminearum were harvested from Czapek liquid mediums after 3 days incubation and weighted after drying. Concentration of osthol in Czapek mediums was 0, 6.25, 12.5, 25, 50 and $100 \mu \mathrm{g} \cdot \mathrm{mL}^{-1}$ respectively. Each value is the mean \pm S.E. for $\mathrm{n}=3$.

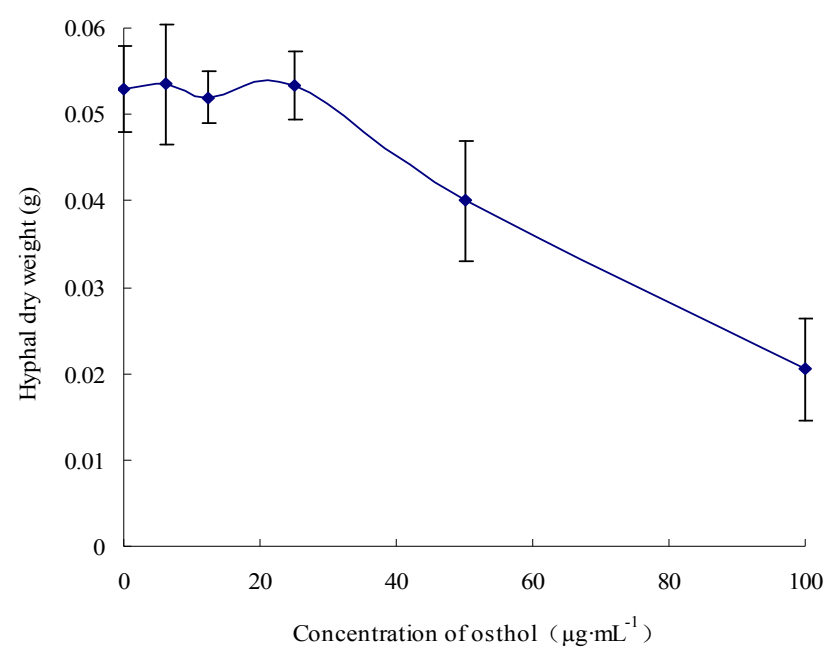


Figure 3. Hyphal fragments appeared in aqueous Czapek culture when F. graminearum hyphae were treated with osthol for 24 hours. A, solvent control; B, treatment with 100 $\mu \mathrm{g} \cdot \mathrm{mL}^{-1}$ osthol. Bar $=50 \mu \mathrm{m}$.
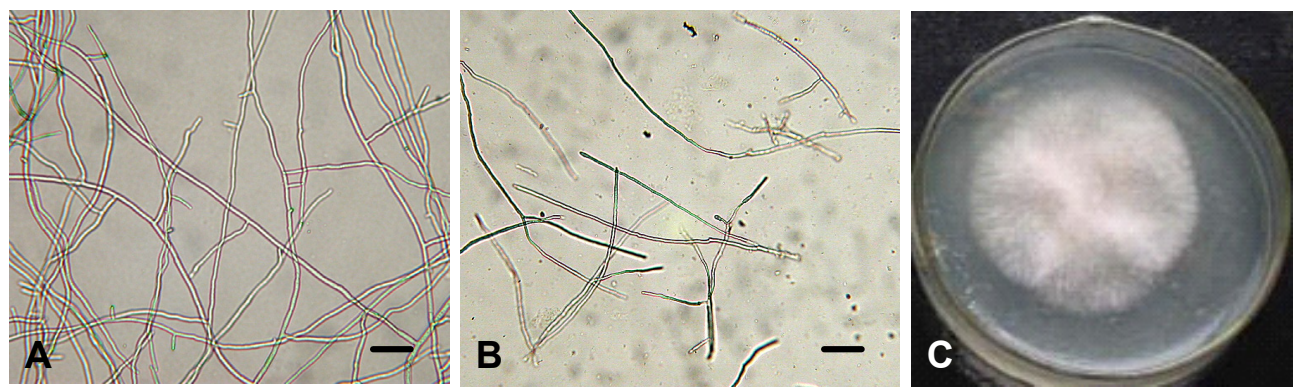

Figure 4. Transmission electron microscope (TEM) analysis showing morphology changes of hyphae of $F$. graminearum after treated with $100 \mu \mathrm{g} \cdot \mathrm{mL}^{-1}$ osthol for $24 \mathrm{~h}$. A) blank control; B) and D) solvent control; C) and E) treated with $100 \mu \mathrm{g} \cdot \mathrm{mL}^{-1}$ osthol. Bar $=1 \mu \mathrm{m}$.

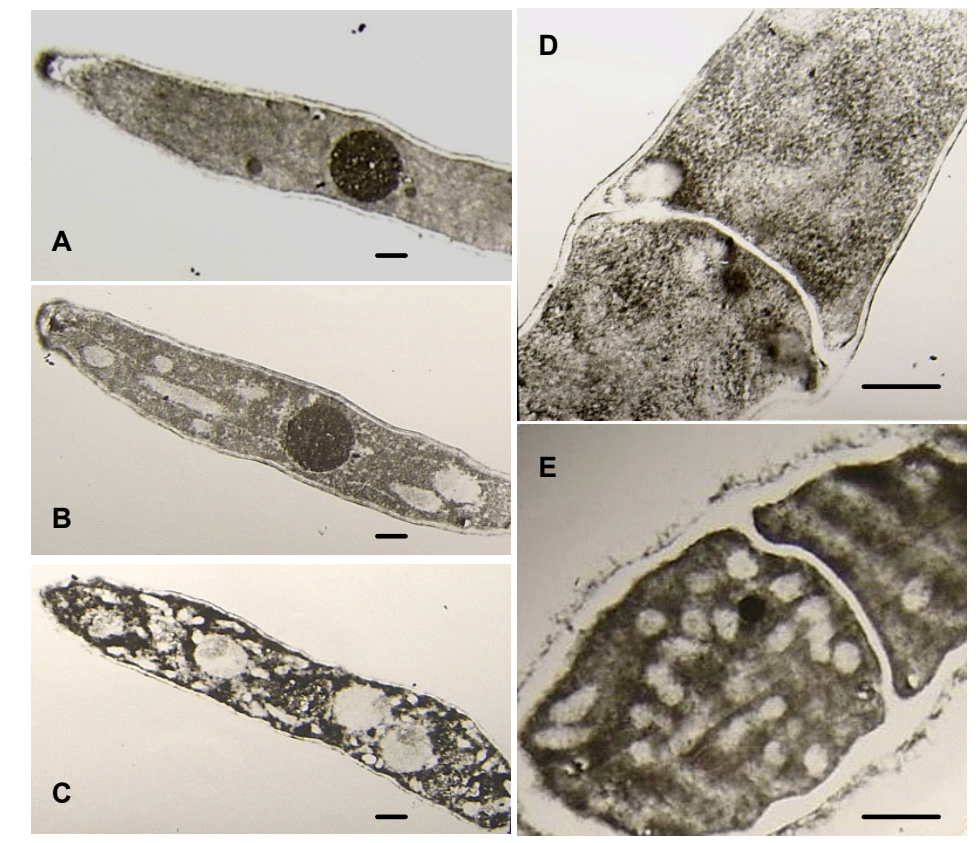

\subsubsection{Effects of osthol on hyphal glucose absorption}

An effect of osthol on hyphal glucose utilization was detected. As shown in Figure 5, within the osthol-treated hyphae reducing sugar levels decreased to the lowest value after $3 \mathrm{~h}$ and recovered to the control level $6 \mathrm{~h}$ after the treatment. By thin-layer chromatography (TLC) analysis, we found that the reducing sugar in hyphae of $F$. graminearum was mainly composed of glucose (Figure 6). Therefore,

${ }^{14} \mathrm{C}$-labelled glucose was used to investigate the glucose absorption of hyphae. Figure 7 suggests that there is an inhibitory effect of osthol on glucose absorption by hyphae at the beginning stages of the treatment. After longer exposure periods the content of ${ }^{14} \mathrm{C}$-labelled glucose in osthol-treated hyphae increased very slowly, while in the control samples the soluble ${ }^{14} \mathrm{C}$ remained at the high beginning 
level of the experiment indicating the effective absorption of glucose by the hyphae. The decrease of the hyphal soluble ${ }^{14} \mathrm{C}$ in control appeared earlier than in the osthol treated samples. These results not only showed a comparatively slow ${ }^{14} \mathrm{C}$-labelled glucose accumulation in osthol-treated hyphae but also indicated that the transformation rate of ${ }^{14} \mathrm{C}$ switching from soluble form to insoluble form was slower than the control.

Figure 5. Effect of osthol on hyphal reducing sugar content. " sugar content in non-osthol-treated hyphae of F. graminearum; "口" represent the reducing sugar content in hyphae of $F$. graminearum with the treatment of $100 \mu \mathrm{g} \cdot \mathrm{mL}^{-1}$ osthol.

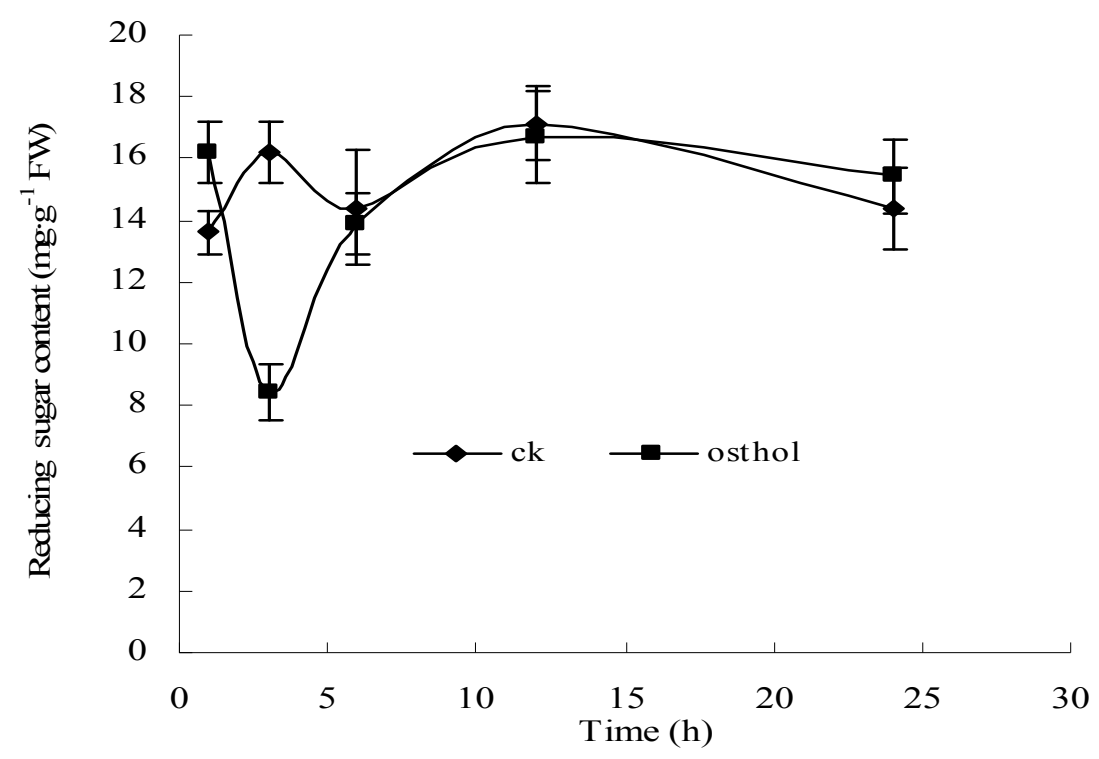

Figure 6. TLC analysis of reducing sugar in hypha of $F$. graminearum. A, B, C, D, E are non-osthol-treated control hyphal reducing sugar spots at 1, 3, 6, 12, $24 \mathrm{~h}$, respectively; $\mathrm{a}, \mathrm{b}$, $\mathrm{c}, \mathrm{d}$, e are osthol-treated hyphal reducing sugar spots at 1, 3, 6, 12, $24 \mathrm{~h}$, respectively after treated with $100 \mu \mathrm{g} \cdot \mathrm{mL}^{-1}$ osthol; $\mathrm{M}$ is the mixture of standard reducing sugars.

Xylose

Glucose

$\begin{array}{lllllllllll}\text { A } & \text { a } & \text { B } & \text { b } & \text { C } & \text { C } & \text { D } & d & E & \text { e } & M\end{array}$ 
Figure 7. Effect of osthol on ${ }^{14} \mathrm{C}$-labeled glucose absorption by the hyphae of $F$. graminearum. The absorbed ${ }^{14} \mathrm{C}$-labeled glucose in untreated hyphae of $F$. graminearum, *; the content of ${ }^{14} \mathrm{C}$-labeled glucose in hyphae of $F$. graminearum with the treatment of $100 \mu \mathrm{g} \cdot \mathrm{mL}^{-1}$ osthol,

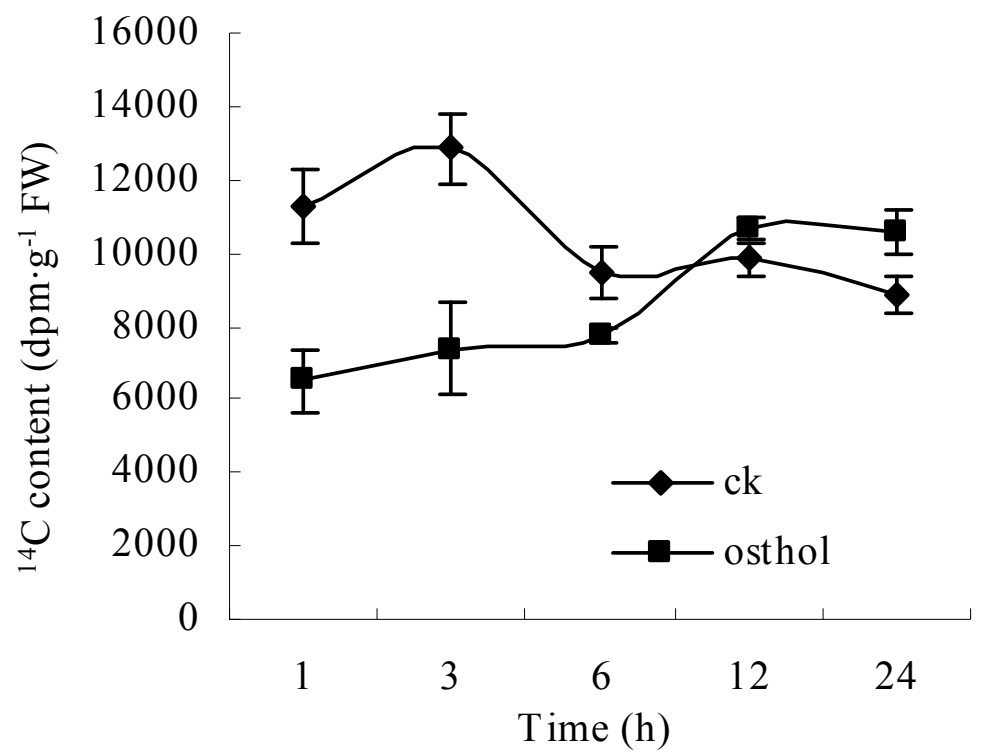

\subsubsection{Influence of osthol on cell wall synthesis-related components}

Morphology observations showed that osthol could cause hyphal cell wall loosening and hyphae breakage. Thereby, components and synthesis-related enzymes of cell wall were examined after hypae were treated with osthol. Figures 8 and 9 show that after treatment with $100 \mu \mathrm{g} \cdot \mathrm{mL}^{-1}$ osthol, chitinase activity and $N$-acetyl-D-glucosamine in osthol-treated hyphae were both higher than in that of the controls. Especially, chitinase activity in osthol-treated hyphae reached the highest level at $3 \mathrm{~h}$ after the beginning of the treatment. However, $\beta$-1,6-glucanase activity showed no obvious difference compared with the control (Figure 10).

Figure 8. Influence of osthol on chitinase activity in hyphae of $F$. graminearum. Chitinase activity in untreated hyphae of $F$. graminearum, $\$$; Chitinase activity in the hyphae of F. graminearum with the treatment of $100 \mu \mathrm{g} \cdot \mathrm{mL}^{-1}$ osthol,

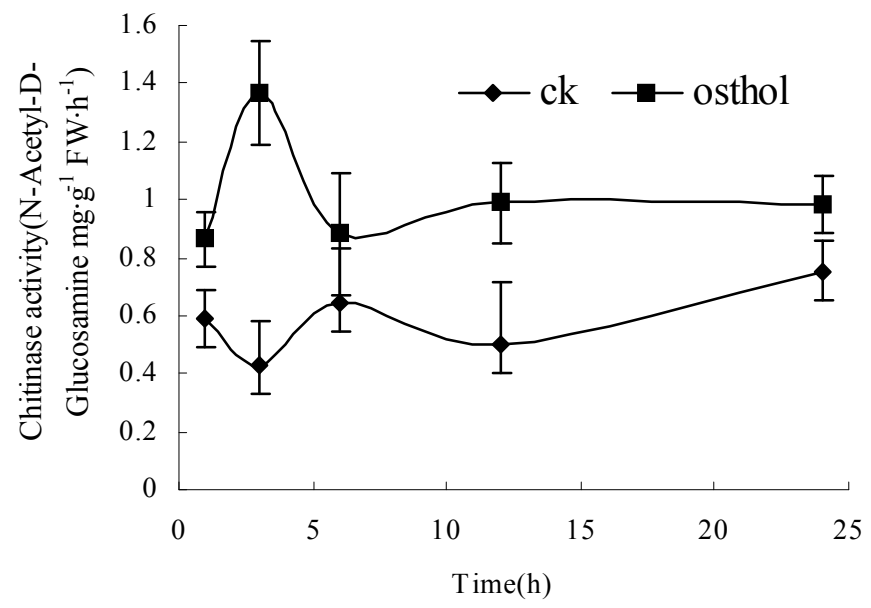


Figure 9. The change of $N$-acetyl-D-glucosamine content in osthol-treated $F$. graminearum. N-Acetyl-D-glucosamine content in untreated hyphae of F. graminearum, $\checkmark$; $N$-Acetyl-D-glucosamine content in the hyphae of $F$. graminearum with the treatment of $100 \mu \mathrm{g}$ mL-1 osthol,

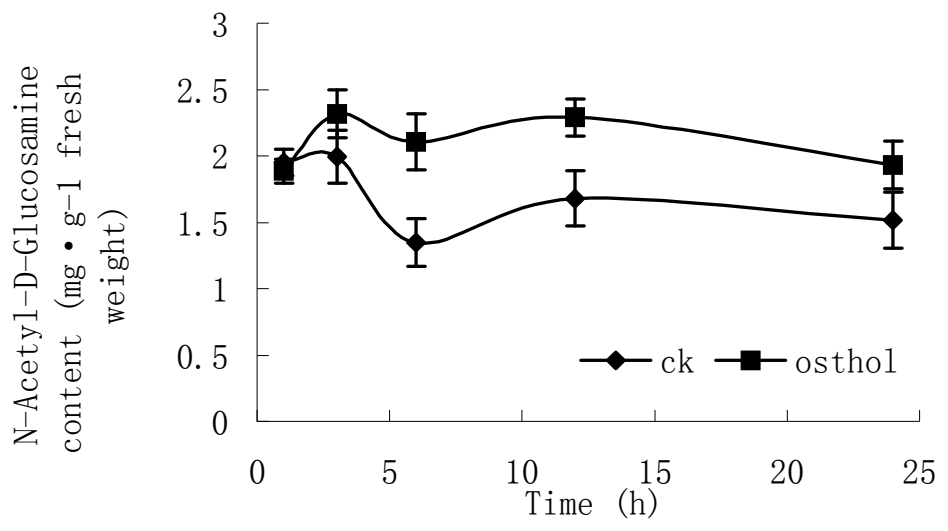

Figure 10. Time course of $\beta$-1,6-glucanase activity in osthol-treated hyphae of $F$. graminearum. $\beta$-1,6-Glucanase activity in untreated hyphae of $F$. graminearum, $\beta$-1,6-glucanase activity in the hyphae of $F$. graminearum with the treatment of $100 \mu \mathrm{g} \cdot \mathrm{mL}^{-1}$ osthol,

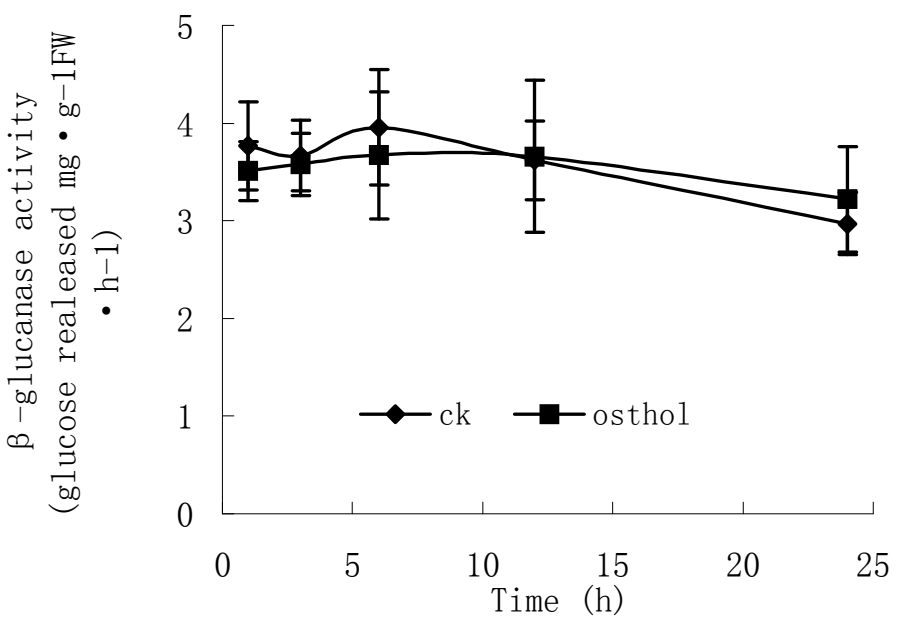

\subsection{Discussion}

Osthol displayed a broad-spectrum antifungal activity against phytopathogens [10]. Bioassay demonstrated that osthol showed a high activity against $F$. graminearum (Figures 1-3) and the in vitro assays in this study also indicated that osthol could inhibit hyphal growth of $F$. graminearum. Treated with $100 \mu \mathrm{g} \cdot \mathrm{mL}^{-1}$ osthol for $24 \mathrm{~h}$, the hyphae of $F$. graminearum growing in aqueous culture broke into fragments and the fragments could develop to colonies after inoculation (Figure 3C). This indicated that the treatment inhibited the growth of the fungi, but was not lethal to them.

The morphological observations showed cytoplasmic vacuolation and blurring of organelles and cell walls after the treatment with osthol (Figure 4). The fungal cell wall consists basically of a complex network of glucan and chitin, playing important roles in several biological processes such as 
cell shape, morphogenesis, reproduction, cell-cell and cell-matrix interaction, and osmotic, physical protection.

The fungal cell wall is critical for cell viability and pathogenicity. Chitin and $\beta$-1,6-glucanase in the cell wall of $F$. graminearum both confer a high mechanical resistance to the cell wall. In previous study, Chaffin and Lopez-Ribot [11] found that chitin was important although only a low content $(0.6 \%-9 \%)$ could be found in the wall of Candida albicans (mainly in the septum of the hyphae). When the fragments appeared after treated with osthol, the components of cell wall of hyphae and hydrolysis-relative enzymes were measured. The results showed that the chitinase activity increased after the treatment with osthol compared with the control and that $N$-GlcNAc, the chitin unit, remained to a high content in the hyphae. However, $\beta$-1,6-glucanase activity did not obviously change (Figure 79), which indicated that osthol treatment could not activate the up-regulated expression of glucanase genes in hyphae of F. graminearum. So glucan, the important component within cell wall, was not hydrolyzed due to the stabilization of glucanolytic activities. In agreement with this, the results of the TEM experiments (Figure 4) showed clearly that the blurring of cell wall after treated with osthol was mainly caused by the hydrolyzation of chitin in the wall. Hence, the broken hyphae appeared due to the loosing of cell wall together with the water flow pressure in liquid medium (Figure 3B).

As a necessary component of cell wall, chitin could be hydrolyzed when sugar starvation occurred [12]. A previous report had demonstrated that the coumarin compounds could inhibit the glucose absorption by $N$. frontalis [13]. In the present study, decreasing glucose content led to changes to $\mathrm{V}$-shaped form in osthol-treated hyphae of $F$. graminearum suggesting a starvation and a recovery of nutrient (Figure 5). From assay of morphology observation, the large vesicles in osthol-treated hyphae indicated that the treatment of osthol might originate glucose starvation [14]. The origin of the starvation might be the inability of nutrient absorption caused by osthol. The results of the trial about ${ }^{14} \mathrm{C}$-labeled glucose absorption agree with this conclusion (Figure 7). When cells of fungi encounter stress or unfavorable nutrient conditions, the changes of cell were physiologically and morphologically different from the cells growing exponentially. Especially sugar starvation initiates changes in substantial physiological and biochemical processes with the goal of sustaining respiration and other essential metabolic processes [15].

The results also showed that plenty of vacuoles appeared in the osthol-treated hyphae (Figure 4). Autophagy was the major route which cells require enhanced structural compounds degradation and remodeling of components for the maintenance of viability of fungi under starvation conditions $[16,17]$.

Although basic activity of osthol against the phytopathogen and some changes of physiological activity were reported herein, further detailed research should be focused on direct targets in the phytopathogenic cells. 


\section{Experimental Section}

\subsection{Chemicals and fungal strain}

Osthol $(97.5 \%, \mathrm{w} / \mathrm{v})$ was extracted by Plant Protection Institute of Jiangsu Academy of Agricultural Sciences (PPIJA); DMAB ( $p$-dimethylaminobenzaldehyde) was purchased from ShangHai SSS Reagent CO., LTD; chitin was purchased from Shanghai Chemical Reagent Corporation; ${ }^{14} \mathrm{C}$-labeled glucose was purchased from China Isotope Corporation; DNS (3,5dinitrosalicylic acid), ATP (adenosine 5'-triphosphate), $\beta$-1,6-glucan, GlcNAc ( $N$-acetyl-Dglucosamine), DMSO (dimethyl sulfoxide), Triton X-100, PPO (2,5-diphenyloxazole), POPOP (1,4bis(5-phenyloxazol-2-yl)benzene) and all other chemicals were obtained from Sigma. Osthol was dissolved in DMSO and prepared as osthol stock solution $\left(20,000 \mu \mathrm{g} \cdot \mathrm{mL}^{-1}\right)$ which was used in the trials. F. graminearum was presented by PPIJA and maintained on potato dextrose agar (PDA) medium at $4{ }^{\circ} \mathrm{C}$.

\subsection{Antifungal activity assays}

Antifungal activity of osthol against $F$. graminearum was determined by inhibition of radial growth and biomass of the fungus in vitro, respectively. The disc diffusion assay was performed in radiation sterilized $\left({ }^{14} \mathrm{C}\right.$-labeled glucose) petri plates of $90 \mathrm{~mm}$ in diameter. Osthol stock solution was added to autoclaved PDA mediums to the final concentrations of $0,6.25,12.5,25,50$ and $100 \mu \mathrm{g} \cdot \mathrm{mL}^{-1}$ just before the curdle of mediums, and then 5-mm discs of the growing fungus were inoculated at the center of $90 \mathrm{~mm}$-diameter Petri plates, respectively. The plates were incubated at $25{ }^{\circ} \mathrm{C}$ and the radial growths were observed in $48 \mathrm{~h}$ intervals.

Osthol was added to Czapek liquor media $(50 \mathrm{~mL})$ in flasks to the final concentrations of $0,6.25$, $12.5,25,50$ and $100 \mu \mathrm{g} \cdot \mathrm{mL}^{-1}$, respectively. Each flask were inoculated with a $5-\mathrm{mm}$ disc of $F$. graminearum and incubated at $25^{\circ} \mathrm{C}$ in a rotary shaker of $140 \mathrm{rpm}$. Mycelium was harvested from each medium after $72 \mathrm{~h}$, oven-dried, and the biomass was recorded.

At the same time, equal volumes of DMSO without osthol were also used as solvent controls in the same treatment. All experiments (including the following experiments) were repeated three times and each one experiment was done in triplicates.

\subsection{Effect of osthol on hyphal morphology}

The effects of osthol on the hyphal structure of $F$. graminearum were observed by light and transmission electron microscope (TEM). Osthol was added to incubation shaking flasks of $F$. graminearum to the final concentration of $100 \mu \mathrm{g} \cdot \mathrm{mL}^{-1}$ three days after inoculation. Mycelium was harvested for morphology observation 24 hours after the treatment. For transmission electron microscopy (TEM), the samples were infiltrated, embedded with Epon-Araldite and polymerized at $60{ }^{\circ} \mathrm{C}$ for $24 \mathrm{~h}$. Ultrathin sections of the samples were cut with a diamond knife and collected on 200-mesh copper grids. After contrasting with uranyl acetate and lead citrate, the grids were examined with a HITACHI H-600 electron microscope at 75KV [18]. 


\subsection{Preparation of hyphae}

The pathogen $F$. graminearum was grown on potato dextrose agar (PDA) at $28{ }^{\circ} \mathrm{C}$ for 5 days and the $10 \mathrm{~mm}$ mycelial plates were inoculated into $500 \mathrm{~mL}$ flasks containing sterilized Czapek culture medium $(250 \mathrm{~mL}) . F$. graminearum were cultured in flasks at $25^{\circ} \mathrm{C}, 140 \mathrm{rpm}$ for $72 \mathrm{~h}$, and then were treated with osthol at a final concentration of $100 \mu \mathrm{g} \cdot \mathrm{mL}^{-1}$. After $1,3,6,12$ and $24 \mathrm{~h}$ treatment, mycelial modality was observed separately. The harvested hyphal materials were stored in a refrigerator at $-80^{\circ} \mathrm{C}$ for the following trials.

\subsection{Determining the mycelial of $F$. graminearum absorbed ${ }^{14} C$-labelled glucose}

Hyphae plates of $F$. graminearum grown on PDA medium were inoculated in Czapek culture medium in shake flasks and incubated at $25^{\circ} \mathrm{C}, 140 \mathrm{rpm}$ for $72 \mathrm{~h}$ and $15 \mu \mathrm{L} 303.00 \mathrm{~m} \mathrm{Ci} / \mathrm{mmol}$ ${ }^{14} \mathrm{C}$-labelled glucose were added thereafter. Then the hyphae in the culture medium were treated with osthol at a final concentration of $100 \mu \mathrm{g} \cdot \mathrm{mL}^{-1}$. After incubation for $1,3,6,12$ and $24 \mathrm{~h}$, the hyphae were sampled and filtered through filter paper and stored at $-20^{\circ} \mathrm{C}$. Hyphae from osthol-free mediums were used as control.

Scintillator solution: 5 g PPO (2,5-diphenyloxazole), 0.5 g POPOP (1,4-bis(5-phenyl-2-oxazolyl) benzene) were dissolved in toluene respectively mixed with $300 \mathrm{~mL}$ Triton X-100 and made up with toluene to a final volume of $1000 \mathrm{~mL}$.

Accurately weighed $0.1 \mathrm{~g}$ freeze dried mycelial samples were homogenized by hand with Tris- $\mathrm{HCl}$ $(0.05 \mathrm{M}, \mathrm{pH}=7.5,1 \mathrm{~mL})$, then the homogenate was centrifuged at $10000 \mathrm{rpm}$ for $10 \mathrm{~min}$ at $4{ }^{\circ} \mathrm{C}$. Supernatant $(0.1 \mathrm{~mL})$ was were mixed with scintillator solution $(6 \mathrm{~mL})$ and measured by scintillation counter. [19].

\subsection{Determination of reducing sugar}

For each treatment, mycelial material ( $0.4 \mathrm{~g}$ dry weight) was homogenized in extraction solution

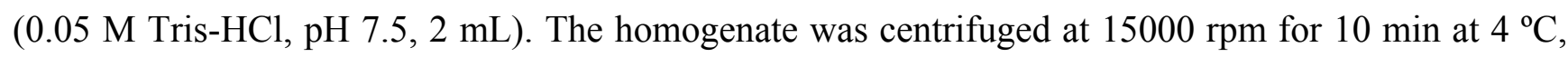
and the supernatant was used for the following trials. Supernatant $(0.1 \mathrm{~mL})$ was carefully transferred into an Eppendorf tube, and then DNS reagent $(2.0 \mathrm{~mL})$ was added to the ED tube. The tubes were heated at $100{ }^{\circ} \mathrm{C}$ in a water bath for 5 minutes, cooled down to room temperature and filled up to a predetermined volume of $25 \mathrm{~mL}$. At the same time, distilled water $(0.1 \mathrm{~mL})$ plus DNS reagent $(2.0$ $\mathrm{mL}$ ) were treated as described above and served as blank sample for zeroing of the spectrophotomater. Three repeats were carried out in each treatment and a glucose standard curve was prepared at a wavelength of $595 \mathrm{~nm}$ for calibration purposes [20].

\subsection{Determination of N-Acetyl-D-Glucosamine}

Supernatant liquid $(0.2 \mathrm{~mL})$ was treated with potassium borate solution $(0.8 \mathrm{M}, 0.1 \mathrm{~mL})$ and the mixture was placed in a boiling water bath for $3 \mathrm{~min}$. After cooling down, 1\% DMAB (3 mL) was added and the samples were kept at $36{ }^{\circ} \mathrm{C}$ for $20 \mathrm{~min}$. The absorbencies of the samples were detected at $544 \mathrm{~nm}$ using a spectrophotometer. Three repeats were carried out in each treatment and $\mathrm{N}$-acetyl-D-glucosamine was used to make the standard curve [21]. 


\subsection{Analysis of chitinase}

Gelatiniform chitin (N-acetylation product of chitosan, $0.2 \mathrm{~mL}$ ) was added to supernatant liquid $\left(0.3 \mathrm{~mL}\right.$ from 2.5) and the mixture were kept at $37^{\circ} \mathrm{C}$ for $1 \mathrm{~h}$ and inactivated in boiling water for 5 min. After centrifugation at $5000 \mathrm{rpm}$ for $10 \mathrm{~min}$, supernatant liquid $(0.2 \mathrm{~mL})$ was kept in a boiling water bath for $3 \mathrm{~min}$. After cooling down, potassium borate solution $(0.8 \mathrm{M}, 0.1 \mathrm{~mL})$ and 1\% DMAB $(3 \mathrm{~mL})$ were added. After incubation at $36{ }^{\circ} \mathrm{C}$ for $20 \mathrm{~min}$, the values of absorbency for each treated sample were detected at $544 \mathrm{~nm}$ using a spectrophotometer. Three repeats were carried out in each treatment and $N$-acetyl-D-glucosamine was used to make the standard curve [22].

\subsection{Analysis of $\beta$-1,6-glucanase activity}

To supernatant liquid $(0.3 \mathrm{~mL}$ from 2.5$) 1 \% \beta$-1,6-glucanase $(0.4 \mathrm{~mL})$ was added and the mixture was kept at $40{ }^{\circ} \mathrm{C}$ for $5 \mathrm{~min}$, and then DNS $(2 \mathrm{~mL})$ was added. After incubation for $5 \mathrm{~min}$ in a boiling water bath and cooling down to the room temperature, the absorbance values for each treated sample were detected at $595 \mathrm{~nm}$ using a spectrophotometer. Three repeats were carried out in each treatment and glucose was used to make the standard curve [23].

\section{Acknowledgements}

This research was supported by the National Natural Science Foundation of China (30471125). The authors thank Professor Shun Jianzhong for critically reading the manuscript.

\section{References}

1. Parry D.W.; Jenkinson, P.; McLeod, L. Fusarium ear blight (scab) in small grain cereals - a review. Plant Pathol. 1995, 44, 207-238.

2. Jianxin, W.; Mingguo, Z.; Yuejian, L.; Zhongyin, Y. Dynamics of resistant population of Fusarium graminearum to carbendazim and substitutable fungicide screening. J. Nanjing Agric. Univ. 2002, 25, 43-47.

3. Dan, W.; Huazhi, Y.; Yun, Q. The resistance of Fusarium graminearum to Carbendazim in Sichuan. Agrochemicals 2007, 46, 560-562.

4. Various. Pharmacopoeia of the People's Republic of China, English Edition; Chemical Industry Press: Beijing, P.R. China, 1997; pp. 62-63.

5. Ou, M. Chinese-English manual of commonly used traditional Chinese medicine; Joint Publishing Co. Ltd.: Hong Kong, 1989.

6. Yamahara, J.; Kozuka, M.; Sawada, T.; Fujimura, H.; Nakano, K.; Tomimatsu, T.; Nohara, T. Biologically active principles of crude drugs. Anti-allergic principles in "Cnidii monnieri" Chem. Pharm. Bull. 1985, 33, 1676-1680.

7. Matsuda, H.; Tomohiro, N.; Ido, Y.; Kubo, M. Anti-allergic effects of Cnidii Monnieri fructus (dried fruits of Cnidium monnierz) and its major component, osthol. Biol. Pharm. Bull. 2002, 25, 809-812. 
8. Liao, J.M.; Zhu, Q.A.; Lu, H.J.; Li, Q.N.; Wu, T.; Huang, L.F. Effects of total coumarins of Cnidium monnieri on bone density and biomechanics of glucocorticoids induced osteoporosis in rats. Acta Pharmacol. Sin. 1997, 18, 519-521.

9. Shukla, Y.N.; Srivatava, A. Phytotoxic and antimicrobial constiuents of Argyreia speciosa and Oenothera biennes. Ethnopharmacology 1986, 67, 241-245.

10. Shi, Z.Q.; Shen, S.G.; Xu, L.L.; Fan, Y.J. Inhibition Mechanism of Osthol to Plant Fungus Pathogens. Chin. J. Pest. Sci. 2004, 6, 28-32.

11. Chaffin, W.L.; J.L. Lopez-Ribot; M. Casanova; D. Gozalbo; J.P. MartÌnez. Cell wall and secreted proteins of Candida albicans: identification, function and expression. Microbiology and Molecular Biology Reviews 1998, 62, 130-180.

12. Donzelli, B.G.G.; Harman, G.E. Interaction of ammonium, glucose, and chitin regulates the expression of cell wall-degrading enzymes in Trichoderma atroviride strain P1. Appl. Environ. Microbiol. 2001, 67, 5643-5647.

13. Moniello, G.; Richardson, A.J. Effects of coumarin and sparteine on attachment to cellulose and cellulolysis by Neocallimastix frontalis RE1. Appl. Environ. Microbiol. 1996, 62, 4666-4668.

14. Yuan, W.P.; Strømhaug, P.E. Glucose-induced Autophagy of Peroxisomes in Pichia pastoris Requires a Unique E1-like Protein. Mol. Biol.Cell 1999, 10, 1353-1366.

15. Yu, S.M. Cellular and genetic responses of plants to sugar starvation. Plant Physiol. 1999, 121, 687-693.

16. Dunn, W.J. Autophagy and related mechanisms of lysosome-mediated protein degradation. Trends Cell Biol. 1994, 4, 139-143

17. Matsuura, A.; Tsukada, M.; Wada, Y.; Ohsumi, Y. Apg1p, anovel protein kinase required for the autophagic process in Saccharomyces cerevisiae. Gene 1997, 192, 245-250

18. Celio, G.J.; Mims, C.W.; Richardson, E.A. Ultrastructure and immunocytochemistry of the hostpathogen interface in poinsettia leaves infected with powdery mildew. Can. J. Bot. 2004, 82, 421429.

19. Marqueze, A.; Kucharski, L.C.; Da Silva, R. Effects of anoxia and post-anoxia recovery on carbohydrate metabolism in the jaw muscle of the crab Chasmagnathus granulatus maintained on carbohydrate-rich or high-protein diets. J. Exp. Mar. Biol. Ecol. 2005, 332, 198-205.

20. Miller, G.L. Use of dinitrosalicylic acid reagent for the determination of reducing sugar. Anal. Chem. 1959, 31, 426-428.

21. Ciopraga, J.; Gozia, O.; Tudor, R.; Brezuica, L.; Doyle, R.J. Fusarium sp. growth inhibition by wheat germ agglutinin. Biochim. Biophys. Acta-Gen. Subj. 1999, 1428, 424-432.

22. Elad, Y.; Chet, I.; Henis, Y. Degradation of plant pathogenic fungi by Trichoderma harzianum. Can. J. Microbiol.1982, 28, 719-725.

23. Shi, Y.M. Introduction of modern plants physiology experiments; Science Press: Beijing, P.R. China, 1999; p. 12.

(C) 2008 by MDPI (http://www.mdpi.org). Reproduction is permitted for noncommercial purposes. 